\title{
Aspectos nutricionais do amido da Maranta arundinacea L. na formulação de pães sem glúten
}

\author{
Nutritional aspects of Maranta arundinacea L. starch in the formulation of \\ gluten-free breads
}

Nayara Andrade de Oliveira; Vanessa de Oliveira Almeida*

Faculdade Maria Milza - FAMAM, Governador Mangabeira - Bahia, Brasil, 44350-000, nayandrade2009@hotmail.com; https://orcid.org/0000-0003-3479-7962;

*Autor correspondente: voagro@gmail.com; https://orcid.org/0000-0002-9742-4429

\section{Resumo}

Muitas espécies da flora brasileira são subutilizadas, incluindo a araruta (Maranta arundinacea L.), planta com rizoma rico em amido com alto valor nutricional de importância cultural para a região do Recôncavo da Bahia, Brasil. O objetivo deste trabalho foi analisar os aspectos nutricionais da inclusão do amido de araruta em pão sem glúten enriquecido com farinha de bagaço de laranja. Foram elaboradas três formulações de pães sem glúten: sem o amido da araruta (controle); e duas formulações teste: F1 com 100\% de farinha de araruta e F2 com 33\% de farinha de araruta, $33 \%$ de fécula de batata e $33 \%$ de farinha de arroz; e feita a comparação estatística entre estes três tratamentos, utilizando os seguintes testes estatísticos: Shapiro-Wilk, análise de variância e Tukey. Os resultados mostraram que a inclusão do amido de araruta em pães sem glúten alterou seu teor de umidade, aumentaram o teor de carboidratos e reduziu o teor de proteína; o teor de gordura foi baixo nas três formulações e todas apresentaram teores satisfatórios de fibras. Diante desses resultados, e à luz da literatura, conclui-se que a inclusão do amido de araruta na formulação de pães sem glúten enriquecidos com farinha de bagaço de laranja é uma alternativa nutricionalmente viável. O uso da araruta incentiva seu cultivo e a preservação dessa espécie na biodiversidade local, trazendo benefícios econômicos para a região, a inclusão da farinha de bagaço de laranja nos alimentos aumenta seu valor nutritivo e evita seu desperdício e acúmulo no ambiente.

Palavras chave: araruta, resíduo de laranja, sustentabilidade. 


\begin{abstract}
Many species of the Brazilian flora are underutilized, including the arrowroot (Maranta arundinacea L.), a starch-rich rhizome plant with high nutritional value of cultural importance for the Reconcavo da Bahia region, Brazil. The objective of this work was to analyze the nutritional aspects of including arrowroot starch in gluten-free bread enriched with orange pomace flour. Three gluten-free bread formulations were prepared: without arrowroot starch (control); and two test formulations: F1 with 100\% arrowroot flour and F2 with $33 \%$ arrowroot flour, 33\% potato starch and 33\% rice flour; and made a statistical comparison between these three treatments, using the following statistical tests: Shapiro-Wilk, analysis of variance and Tukey. The results showed that the inclusion of arrowroot starch in gluten-free breads altered its moisture content, increased its carbohydrate content and reduced its protein content; the fat content was low in the three formulations and all had satisfactory fiber contents. In view of these results, and in light of the literature, it is concluded that the inclusion of arrowroot starch in the formulation of gluten-free breads enriched with orange pomace flour is a nutritionally viable alternative. The use of arrowroot encourages its cultivation and the preservation of this species in the local biodiversity, bringing economic benefits to the region, the inclusion of orange bagasse flour in food increases its nutritional value and prevents its waste and accumulation in the environment.
\end{abstract}

Keywords: arrowroot, orange residue, sustainability.

\title{
1. Introdução
}

O Brasil é um país que possui uma flora com grande diversidade biológica, algumas das maiores do mundo, mas muitas espécies vegetais com potencial econômico, nutricional e tecnológico ainda são pouco exploradas (Mendes, 2015; Bolzani, 2016; Scaramuzza, 2016). Dentre essas espécies está Maranta arundinacea L. (Araruta), cujo rizoma é rico em amido de alto valor nutricional, atualmente subutilizado pela indústria de alimentos com poucos estudos sobre esta espécie e dados de seu cultivo (Cunha, 2016).

Segundo Horstmann et al. (2017) a investigação do uso de amidos não convencionais como amido de araruta na formulação de pães sem glúten pode revelar ingredientes para melhorar a qualidade desse produto para atender a população celíaca, intolerante, alérgica a essa proteína ou deseja removê-lo de sua dieta. Além disso, o amido de colmo apresenta alta resistência aos ciclos de congelamento / descongelamento, característica interessante para a indústria que precisa atender às novas demandas do mercado consumidor de alimentos pré-preparados (Madineni et al., 2012).

Por outro lado, a produção de alimentos que atendam aos requisitos de sustentabilidade 
ambiental, gerando menor impacto no meio ambiente, tem se tornado cada vez mais atrativa para o mercado consumidor (De Toni et al., 2013).

Nesse sentido, muitos autores têm utilizado a farinha de resíduo de Citrus sinensis (laranja) para o preparo de produtos alimentícios, visto que o desperdício de dejetos vegetais representa uma perda de oportunidade de melhorar a situação da segurança alimentar mundial e causa impactos ambientais negativos também sobre como o uso da terra, biodiversidade, clima, água, solo e questões econômicas e de uso do solo (FAO, 2013; Silva et al., 2013; O’Shea et al., 2013; Ferreira et al., 2015; Charles et al., 2016).

Para Varzakas et al. (2016) estes resíduos podem ser recuperados para serem empregados na produção de nutracêuticos e alimentos aumentando o teor de fibras destes. Uma vez que, alimentos com a boa quantidade de fibra traz benefícios para a saúde melhorando o trânsito intestinal e a glicemia sanguínea (Gayo, 2013).

Neste contexto, de que forma o amido da Maranta arundinacea L. (araruta) interfere nas características nutricionais quando inserido na composição de pães sem glúten enriquecidos com a farinha do bagaço da laranja?

Sendo assim, este trabalho tem como objetivo estudar os aspectos nutricionais decorrentes da inclusão do amido da araruta na formulação de pães sem glúten enriquecidos com a farinha do bagaço da laranja. Para alcançá-los foram traçados os seguintes objetivos específicos: elaborar a farinha do resíduo da laranja; elaborar um pão sem glúten enriquecido com a farinha de laranja contendo como fontes de amido a farinha de arroz e a fécula de batata (controle), elaborar formulações teste contendo diferentes concentrações do amido de araruta e comparálas com o controle; realizar a análise microbiológica dos tratamentos produzidos.

Esta pesquisa justifica-se pela importância de elaborar um produto sem glúten, rico em fibras destinado às pessoas que não podem consumir esta substância contribuindo para a segurança alimentar e nutricional deste grupo de indivíduos; pela necessidade de fomentar a cultura e o uso da araruta preservando a presença deste item na biodiversidade local, gerando benefícios econômicos e culturais para a região do Recôncavo da Bahia; para aumentar a utilização dos resíduos do suco de laranja reduzindo o acumulo destes resíduos no meio ambiente e agregar valor a este subproduto.

Tanto a araruta como a laranja e seus derivados são produzidos e comercializadas na região 
do Recôncavo Baiano. A laranja é a segunda fruta mais produzida na Bahia, atrás apenas da banana e a produção do suco é muito forte nessa região, mas sem aproveitamento do resíduo. No caso da araruta vem ocorrendo uma redução no seu cultivo e consumo, pois vem perdendo espaço para as féculas da mandioca, trigo e milho, restando poucos produtores desta rica fonte de amido (Silva \& Cavalcante, 2014; Vieira, 2014; Costa, 2015; Cunha, 2016; Carvalho, 2017).

\section{Material e Métodos}

Os estudos foram conduzidos na Faculdade Maria Milza (FAMAM), no município de Governador Mangabeira - BA. A elaboração dos produtos foi realizada no Laboratório de Tecnologia de Alimentos e Nutrição da FAMAM. As análises microbiológicas e bromatológicas foram realizadas no Laboratório de Microbiologia de Alimentos e Água e no Laboratório de Bromatologia da Universidade Federal da Bahia (UFBA) respectivamente.

O desenho experimental consistiu-se no desenvolvimento de quatro etapas:

(1) Obtenção da farinha de araruta e da farinha do bagaço da laranja; (2) Elaboração do pão sem glúten funcional enriquecido com farinha do bagaço da laranja com amido de arroz e batata, conforme a metodologia proposta por O'Shea et al. (2015a) com adaptações (controle); e elaboração de duas $(02)$ formulações $(\mathrm{F} 1, \mathrm{~F} 2)$ de pães sem glúten funcionais enriquecidos com a farinha do bagaço da laranja, conforme a metodologia citada acima. Sendo que na F1 os amidos de arroz e batata foram totalmente substituídos por amido de araruta, e na F2 ocorreu a substituição parcial, contendo 33\% de amido de araruta, 33\% de farinha de arroz e 33\% de fécula de batata; (3) Caracterização bromatológica do pão controle e das 02 formulações teste; (4) Comparação dos aspectos nutricionais (bromatológicos e microbiológicos) de pães sem glúten enriquecidos com a farinha do bagaço da laranja contendo o amido de araruta com o pão sem glúten enriquecido com a farinha do bagaço da laranja elaborado sem o amido desta planta.

O resíduo da laranja utilizado para a elaboração da farinha foi o albedo (parte branca esponjosa), a polpa, a casca e as sementes da laranja tipo pêra (Citrus sinensis) coletado na Lanchonete "Sucão da BR", localizada na BR 101, Km 240, Cruz das Almas/ Ba, Brasil, após a extração do seu suco para comercialização. Os resíduos das laranjas foram lavados em água corrente e posteriormente colocados em solução clorada a 100 ppm por 10 minutos. Em seguida as amostras foram cortadas em fragmentos de $3 \mathrm{~cm}$ e o excesso de umidade foi retirado por 
compreensão utilizando espremedor manual. Em seguida o material foi desidratado em estufa de circulação de ar forçado a $70^{\circ} \mathrm{C}$ por 10 horas, peneirados em malha de $14 \mathrm{~cm}$ e armazenados em frascos de vidro com tampa para posterior adição nas formulações dos pães.

A amostra de pão utilizada como controle foi preparada conforme formulação proposta por O'Shea et al. (2015a), com as seguintes adaptações: sem a adição do amido de araruta, contendo como fontes de amido apenas a farinha de arroz e a fécula de batata. Na formulação controle foram utilizados os seguintes ingredientes: farinha de arroz $600 \mathrm{~g}$; amido (fécula) de batata 600 g; óleo de girassol $72 \mathrm{ml}$; goma xantana 7,2 g; sal $24 \mathrm{~g}$; açúcar demerara $60 \mathrm{~g}$; fermento biológico seco 24 g; bagaço da laranja 64,8 g e água potável filtrada 1.135,2 ml inicialmente foram adicionados em um recipiente os ingredientes secos, incluindo o fermento e misturados por batedeira elétrica, tipo doméstica. Em seguida foram acrescentados água e óleo de girassol, novamente misturados até a formação de uma massa viscosa de $\pm 3 \mathrm{~kg}$ que foram distribuídas uniformemente em assadeiras antiaderentes para pão com 24 x 12,5 x $6 \mathrm{~cm}$. Os tratamentos (formas de pão) com as amostras, incluindo os controles foram assados em forno doméstico por 50 minutos a temperatura $230^{\circ} \mathrm{C}$ com 3 repetições desse experimento.

Foram desenvolvidas duas formulações teste de pães sem glúten enriquecidos com a farinha do bagaço da laranja (F1 e F2), sendo a formulação (F1), preparada com fonte de amido $100 \%$ de farinha de araruta e a formulação (F2) elaborada com 33\% de farinha de araruta, 33\% de fécula de batata e $33 \%$ de farinha de arroz. Os mesmos procedimentos de preparo dos pães foram seguidos nas duas formulações teste, alterando apenas a quantidade da farinha de araruta. Os ingredientes utilizados para obtenção dos pães foram das mesmas marcas nas diferentes formulações, sendo pesados separadamente em balança digital com precisão de $0,1 \mathrm{~g}$. Para todos os ingredientes foram observados a adequação de apresentação e prazo de validade.

Foram realizadas análises bromatológicas com três repetições e em triplicata do pão controle e das formulações teste F1 e F2. Foram realizadas análises de umidade, cinzas, lipídios, carboidratos, fibras e valor calórico utilizando a metodologia proposta pelo Official Methods of Analysis of AOAC International (Horwitz, 2000) e Instituto Adolfo Lutz (Zenebon et al., 2008).

As análises microbiológicas foram realizadas seguindo as diretrizes gerais da resolução da RDC $n^{\circ}$ 12, de 02 de janeiro de 2001, da Agência Nacional de Vigilância Sanitária -ANVISA, 
sobre os padrões microbiológicos para alimentos: Bacillus cereus $/ \mathrm{g}$, coliformes totais a $45^{\circ} \mathrm{C} / \mathrm{g}$ e Salmonella sp./25 g. Para a realização das análises foram seguidas as diretrizes gerais do método APHA (American Public Health Association).

$\mathrm{O}$ experimento foi conduzido em delineamento inteiramente casualizado com três repetições para cada tratamento. Para investigar se o amido da araruta produziu mudanças significativas na qualidade nutricional de pães sem glúten foi necessário submeter os valores encontrados nas análises bromatológica do pão controle, F1 e F2 a três testes estatísticos: o teste de normalidade Shapiro-Wilk, a análise de variância (ANOVA), seguida pelo teste de Tukey. Para realização destas análises foi utilizado o software R, sendo estabelecido um nível de significância estatística de 5\%.

\section{Resultados}

O Teste de Shapiro-Wilk demonstrou que os valores encontrados na análise bromatológica seguem a distribuição normal, o que permitiu a realização do próximo teste, a análise de variância-ANOVA (Martins, 2008).

O resultado do teste ANOVA (Tabela 1) mostrou que as diferentes formulações de pães apresentaram diferentes comportamentos com nível de significância de $1 \%$ (valor $p<0,01)$ e de $5 \%$ (valor $\mathrm{p}<0,05)$, demonstrando que a inclusão do amido da araruta em pães sem glúten altera as características bromatológicas/ nutricionais dos mesmos, com exceção dos lipídeos.

Tabela 2. Análise de variância das análises bromatológicas do controle e das formulações F1 e F2.

\begin{tabular}{llll}
\hline FV & TRAT & erro & CV (\%) \\
\hline Umidade & $1,29^{* *}$ & 0,20 & 0,96 \\
Minerais & $0,02^{* *}$ & 0,00 & 3,83 \\
Proteínas & $3,12^{* *}$ & 0,02 & 4,64 \\
Lipídios & $0,87^{\mathrm{NS}}$ & 0,17 & 15,17 \\
Carboidratos & $15,73^{* *}$ & 0,00 & 0,12 \\
Valor calórico & $34,38^{* *}$ & 0,04 & 0,10 \\
Fibras alimentares & $1,19^{*}$ & 0,00 & 1,84
\end{tabular}

FV (fator de variação), TRAT (tratamento)** Significativo a 1\% de probabilidade; ns: não significativo ao nível de $5 \%$ pelo teste $\mathrm{T}$; * significativo a $5 \%$ de probabilidade. $\mathrm{CV}=$ coeficiente de variação

A segunda coluna 'TRAT' apresenta significância (**) demonstrando que a variável 
independente, no caso é o amido da araruta, alterou os resultados das variáveis de interesse. Estatisticamente, a inclusão da araruta nos tratamentos não apresentou interferência apenas nos valores de lipídeos.

A terceira coluna "erro" corresponde à margem de erro experimental, quanto menor o valor nesta coluna, mas preciso é o resultado da análise, ocorrendo uma menor variação dentro do tratamento, observa-se que todas as entradas possuem valores próximos ou iguais a zero. $\mathrm{O}$ coeficiente de variação $(\mathrm{CV})$, por sua vez corresponde à dispersão dos valores, quanto menor esses valores, mais precisos se mostram os resultados, e consequentemente maior a qualidade experimental e menores diferenças entre estimativas de médias serão significativas (Filho Cargnelutti \& Storck, 2007).

O terceiro teste realizado: o teste de Tukey possibilitou a identificação das diferenças existentes entre os tratamentos e a intensidade dessas diferenças para as variáveis testadas (umidade, minerais, proteínas, lipídios, carboidratos, valor calórico e fibras).

$\mathrm{Na}$ leitura da Tabela 2, letras diferentes demonstram que houve diferença estatisticamente significante entre o controle, F1 (formulação 01), F2 (formulação 02), e letras iguais que não houve diferença.

Tabela 2. Parâmetros bromatológicos do pão sem glúten para os diferentes tratamentos

\begin{tabular}{lcccc}
\hline Análise & Controle & F1(100\%) & F2 (33\%) & Média \\
\hline Umidade \% & $47,41 \mathrm{ab}$ & $47,44 \mathrm{a}$ & $46,38 \mathrm{~b}$ & 47,12 \\
Carboidratos g/100 g & $40,69 \mathrm{c}$ & $45,24 \mathrm{a}$ & $43,98 \mathrm{~b}$ & 43,30 \\
Lipídios g/100 g & $3,18 \mathrm{a}$ & $2,15 \mathrm{a}$ & $2,94 \mathrm{a}$ & 2,76 \\
Proteínas g/100 g & $3,92 \mathrm{~b}$ & $1,89 \mathrm{c}$ & $2,78 \mathrm{a}$ & 2,86 \\
Cinzas g/100 g & $1,21 \mathrm{a}$ & $1,05 \mathrm{~b}$ & $1,20 \mathrm{a}$ & 1,15 \\
Fibras g/100 g & $3,59 \mathrm{a}$ & $2,23 \mathrm{c}$ & $2,72 \mathrm{~b}$ & 2,86 \\
Valor Calórico Kcal/100 g & $207,06 \mathrm{~b}$ & $207,87 \mathrm{~b}$ & $213,50 \mathrm{a}$ & 209,46 \\
\hline
\end{tabular}

F1 pão contendo $100 \%$ de araruta com relação ao total de amido; F2 pão contendo $33 \%$ de araruta, 33\% fécula de batata e 33\% farinha de arroz. Letras iguais na mesma linha não indicam diferença estatística entre as amostras no nível de significância avaliado, segundo o Teste de Tukey, ao nível de 5\% de probabilidade.

Logo, a inserção do amido da araruta alterou o valor de umidade do pão sem glúten enriquecido com farinha do bagaço da laranja, conferindo maior umidade o que resulta em maior macies e palatabilidade. A inclusão da farinha da araruta também aumentou o teor de carboidrato desses pães, sendo, porém, este carboidrato de boa qualidade nutricional. Com 
relação às proteínas houve uma pequena redução de sua quantidade, mas que pode ser ajustada com a inclusão de ingredientes proteicos. Com relação ao teor de lipídios não houve alterações significativas, porém, todas as formulações apresentaram baixo teor de gorduras e quantidades satisfatórias de fibras. O tratamento que apresentou melhor resultado referente a quantidade de cinzas foi a formulação com $33 \%$ de farinha de arroz, $33 \%$ de fécula de batata e $33 \%$ de farinha de araruta.

Com relação aos resultados da análise microbiológica tanto as amostras do pão sem o amido da araruta (formulação controle) como das formulações F1 e F2 (formulações teste) apresentaram excelentes respostas microbiológicas em análises feitas em laboratório. Os resultados para os micro-organismos pesquisados são apresentados na Tabela 3.

Tabela 3: Análises microbiológicas dos tratamentos

\begin{tabular}{lccc}
\hline \multirow{2}{*}{ Micro-organismo pesquisado } & \multicolumn{3}{c}{ Tratamento } \\
\cline { 2 - 4 } & Controle & F1 & F2 \\
\hline Bacillus cereus $(\mathrm{UFC} / \mathrm{g})$ & $<1,0 \times 10$ & $<1,0 \times 10$ & $<1,0 \times 10$ \\
Coliformes a $45^{\circ} \mathrm{C}(\mathrm{NMP} / \mathrm{g} 1,0 \times 1 \mathrm{NMP} / \mathrm{g})$ & $<3,0$ & $<3,0$ & $<3,0$ \\
Salmonella $\mathrm{sp}(\mathrm{em} 25 \mathrm{~g})$ & Ausência & Ausência & Ausência \\
\hline
\end{tabular}

Os resultados acima estão de acordo com a legislação vigente para produtos de panificação RDC $n^{\circ}$ 12, de 02 de janeiro de 2001 da Agência Nacional de Vigilância Sanitária que estabelece padrões microbiológicos para alimentos.

\section{Discussão}

A araruta alterou o teor de umidade do pão sem glúten, sendo que a formulação com 100\% de araruta (F1) diferiu do tratamento com $33 \%$ de farinha de araruta (F2). O valor de umidade encontrado nesse experimento, em média $47,12 \%$ é maior do que o teor de umidade dos pães tradicionalmente comercializados tipo francês que apresentam, em sua maioria, umidade abaixo de 26\% (Feitosa et al., 2013), porém similar ao encontrado na formulação de pães sem glúten com creme de arroz, fécula de batata e farinha chia, que variaram entre 48,61 $\pm 0,63$ e $50,45 \pm 0,25 \%$ (Pereira et al., 2013).

Maior teor de umidade está relacionado a um melhor padrão de textura e maciez, o que pode contribuir para uma maior aceitação deste pão, isto é muito importante para a indústria 
de pão sem glúten, pois este último geralmente obtém menor aceitação comparado ao pão tipo francês (Feitosa et al., 2013; Padalino et al., 2016).

O teor de umidade pode interferir no tempo possível de armazenamento destes pães reduzindo este tempo, todavia, conforme Madineni et al. (2012), o amido da araruta possui estabilidade a ciclos de congelamento/ descongelamento o que favorece a sua incorporação em alimentos que possam ser armazenados por um maior período de tempo, inclusive pela indústria de alimentos prontos refrigerados.

Quanto ao teor de carboidrato, pode-se observar que a araruta incrementou o teor de carboidrato dos pães sem glúten. O tratamento F1 com 100\% de farinha de araruta do total de amido foi o que apresentou maior teor de carboidratos comparado à F2 e ao controle. Isto pode ser explicado pelo alto teor de carboidrato da fécula da araruta, em torno de 99\% (Costa, 2015).

Contudo, quando o assunto é carboidrato faz-se necessário discutir o tipo e a qualidade deste nutriente, para isso é preciso conhecer a composição deste. Uma parte dos carboidratos estão na forma de amido, o amido é um polissacarídeo composto por amilose (cadeias lineares) e amilopectina (cadeias ramificadas) (Oliveira \& Marchini, 2008).

No caso da araruta o amido possui um maior teor de amilose comparado a outros amidos o que lhe confere uma digestão mais lenta devido as suas cadeias retas, o que é uma vantagem nutricional no controle sanguíneo de glicose e triglicerídeos, o que reduz o risco de obesidade e suas comorbidades (Denardin, 2008).

O teor de carboidrato encontrado no pão de araruta, formulação F1, foi semelhante ao encontrado por Mariani et al. (2015) em biscoitos elaborados com farinha de arroz, farelo de arroz e farinha de soja (48\%).

Outro macronutriente de grande importância para o organismo humano são as proteínas, elas estão presentes na síntese e manutenção dos tecidos, fornecem energia, atuam nas vias metabólicas e imunológicas, no transporte de substancias além de muitas outras funções (Tirapegui, 2013).

A comparação estatística demonstrou que a substituição das farinhas de arroz e de batata pela farinha de araruta pode reduzir o teor de proteínas da formulação, sendo menor teor de proteína do pão F1 (100 \% de araruta), e deste com a relação ao F2 (contendo 33\% de araruta) e ao pão controle, o que lhe confere uma desvantagem nutricional neste aspecto, uma vez que, 
um maior teor de proteína no alimento pode reduzir a velocidade de absorção glicídica e estarem relacionados com aumento da saciedade e da termogênese (Layman \& Baum, 2004).

A formulação F2 apresentou teor de proteína similar ao encontrado por Montes (2014) em biscoitos sem glúten utilizando farinha de tapioca, 2,56\%. Huerta (2015), contudo, conseguiu aumentar o teor de proteínas em pães sem glúten incorporando farinha de chia à composição convencional composta por fécula de batata e de arroz.

Uma outra alternativa para o aumento do teor de proteínas de preparações contendo araruta seria a inclusão de ovos, devido a qualidade nutricional de sua proteína e sua boa aceitação em bolos e produtos de panificação em geral.

Não houve variação significativa entre o controle e as formulações teste no quesito teor de gordura (lipídios), entretanto o valor foi menor do que o valor encontrado por Pereira (2013) em pão sem glúten a base de farinha de arroz e fécula de batata.

A redução do teor de gordura nas dietas é uma vantagem nutricional uma vez que dietas ricas em gordura e carboidratos simples aumentam o risco de obesidade e suas consequências, devido ao aumento dos adipócitos e da atividade inflamatória destes, além de outras alterações bioquímicas maléficas ao organismo (Garcia, 2018; Navarro et al., 2016).

Outra característica relevante é a utilização do óleo de girassol nas preparações, pois óleos vegetais podem ser usados como uma alternativa às gorduras sólidas para produzir produtos de panificação com um perfil de ácidos graxos mais saudável (Tarancón et al., 2014).

Além das qualidades de ser um produto livre de glúten e com boas características nutricionais, existe uma demanda atual para alimentos ricos em fibras. As fibras contribuem para a melhora do fluxo intestinal, sendo que problema de intestino lento, condição clínica chamada de obstipação, atinge crianças, adultos e idosos em todo o mundo (Gayo, 2013).

O consumo de fibras também está associado a um controle glicêmico reduzindo o risco do desenvolvimento de doenças como o diabetes mellitus tipo 2 (Molz et al., 2015). Segundo as Dietary Reference Intakes (DRIs) recomendações de nutrientes e energia, a ingestão diária de fibras de um adulto jovem deve ser em torno de $30 \mathrm{~g}$ (Padovani et al., 2006).

Dados os motivos supracitados nas formulações propostas nesta pesquisa, realizou-se a inclusão da fibra do bagaço da laranja para aumentar o teor de fibras da preparação e otimizar o aproveitamento da laranja. Tanto as formulações F1e F2 como o controle atingiu em 100g, 
cerca de $10 \%$ da ingestão diária de fibras para o um adulto. Esse valor é maior quando comparado a pães sem glúten sem adição de fibras (Anjos et al., 2017), embora a inclusão da farinha de araruta tenha alterado para menos o valor de fibras nas formulações.

A inclusão de fontes de fibras em produtos de panificação também foi realizada por outros autores, Aprodu e Banu (2015) incluíram fontes de fibras em um pão sem glúten a base de milho (farelo de soja, aveia, fibra de ervilha, e Fibra Psyllium) obtendo melhoras na qualidade nutricional e reológicas deste pão.

Em trabalho semelhante, Santos et al. (2010) elaboraram biscoitos com fécula de mandioca e albedo da laranja encontrando teor de fibras similar (2,11\%). Anjos et al. (2017) melhoraram a qualidade nutricional de pães sem glúten com aumento dos teores de fibras $(1,44 \%)$, acrescentando à sua formulação farinha da semente de abóbora.

Nesta mesma perspectiva, a farinha da entrecasca da melancia foi utilizada para o enriquecimento do valor nutricional em biscoitos sem glúten aumentando o teor de fibras destes alimentos e servindo como mecanismo de aproveitando de partes não utilizada desta fruta (Lima et al., 2015).

Com relação ao teor de cinzas, o tratamento que apresentou melhor resultado foi a formulação F2 com 33\% de farinha de arroz, 33\% de fécula de batata e 33\% de farinha de araruta. Já com relação ao valor calórico F1 apresentou menor valor quando comparado a F2. Sendo assim, pode-se concluir que a farinha de araruta é uma opção viável de amido naturalmente sem glúten para a formulação de pães, contudo ainda são necessários novos estudos para determinar e analisar determinados parâmetros físicos e tecnológicos deste pão, como coesividade, volume especifico e porosidade e sua aceitação sensorial.

A inclusão da farinha do bagaço da laranja na formulação de pães sem glúten, por sua vez, permite a utilização integral desta fruta, reduzindo o descarte do seu bagaço no meio ambiente e trazendo benefícios econômicos para a região do Recôncavo da Bahia. Ainda com relação à sustentabilidade ambiental e ao desenvolvimento regional a utilização da Maranta arundinacea na formulação de pães sem glúten fomenta o cultivo e o consumo deste vegetal preservando sua presença na biodiversidade local, fortalecendo a economia e contribuindo para a segurança alimentar e nutricional das pessoas celíacas.

\section{Referências}


Anjos, C. N., Barros, B. H. S., Garcia, E. I. et al. (2017). Desenvolvimento e aceitação de pães sem glúten com farinhas de resíduos de abóbora (Cucurbita moschata). Arquivos de Ciências da Saúde, v. 24, n. 4, p. 58-62. https://doi.org/10.17696/2318-3691.24.4.2017.870

Aprodu, I. \& Banu, I. (2015). Influence of dietary fiber, water, and glucose oxidase on rheological and baking properties of maize-based gluten-free bread. Food Sci Biotechnol, 24, 1301-1307. https://doi.org/10.1007/s10068-015-0167-z

Bolzani, V. S. (2016). Biodiversidade, bioprospecção e inovação no Brasil. Ciência e Cultura, v. 68, n. 1, p. 04-05. http://dx.doi.org/10.21800/2317-66602016000100002

BRASIL. Resolução ANVISA/MS nº 12, de 02 de janeiro de 2001. Aprova o Regulamento técnico sobre padrões microbiológicos para alimentos. https://www.gov.br/agricultura/ptbr/assuntos/inspecao/produtos-vegetal/legislacao-1/biblioteca-de-normas-vinhos-ebebidas/resolucao-rdc-no-12-de-2-de-janeiro-de-2001.pdf

Carvalho, C. (2017). Anuário brasileiro da fruticultura 2017. Santa Cruz do Sul: Gazeta Santa Cruz, 92p. https://www.editoragazeta.com.br/sitewp/wp-content/uploads/2017/03/PDFFruticultura 2017.pdf

Charles, A. L.; Cato, K.; Huang, T. T. C. et al. (2016). Functional properties of arrowroot starch in cassava and sweet potato composite starches. Food Hydrocolloids, v. 53, p. 187-191. https://doi.org/10.1016/j.foodhyd.2015.01.024

Costa, R. A. S. Efeito da adição de hidrocoloides (goma guar e goma xantana) nas propriedades de textura e sinérese de géis de amido de araruta. Dissertação-Mestrado, Programa de Pós-Graduação em Engenharia e Ciência de Alimentos. Universidade Estadual do Sudoeste da Bahia, Bahia, Brasil. 76f. 2015. http://www2.uesb.br/ppg/ppgecal/wpcontent/uploads/2017/04/RAFAEL-ALVES.pdf .

Cunha, A. L. Caracterização do amido da araruta tipos seta e redonda, visando utilização na indústria de alimentos. Dissertação-Mestrado. Programa de Pós-Graduação em Ciência dos Alimentos. Universidade Federal de Lavras, Minas Gerais, Brasil. 112f. 2016. http://repositorio.ufla.br/handle/1/10968 .

De Toni, D.; Larentis, F.; Mattia, A. A. et al. (2013). Configuração da imagem do conceito de produtos ecologicamente corretos. Desenvolvimento e Meio Ambiente, v. 28, p. 173-188. http://dx.doi.org/10.5380/dma.v28i0.31003

Denardin, C. C. Influência do teor de amilose e beneficiamento do arroz na resposta biológica de ratos. Dissertação-Mestrado, Programa de Pós-Graduação em Ciência e Tecnologia de Alimentos. Universidade Federal de Santa Maria. Santa Maria, Brasil. 162f. 2008. http://repositorio.ufsm.br/handle/1/5650 
Feitosa, L. R. G. D. F.; Maciel, J. F.; Barreto, T. A.; Moreira, R. T. et al. (2013). Avaliação de qualidade do pão tipo francês por métodos instrumentais e sensoriais. Semina: Ciências Agrárias, v. 34, n. 2. http://dx.doi.org/10.5433/1679-0359.2013v34n2p693

Ferreira, M. S., Santos, M. C., Moro, T. M. et al. (2015). Formulation and characterization of functional foods based on fruit and vegetable residue flour. Journal of food science and technology, v. 52, n. 2, p. 822-830, 2015. https://doi.org/10.1007/s13197-013-1061-4

Gayo, M. P. F. Obstipação crônica em adultos, do diagnóstico ao tratamento. DissertaçãoMestrado, Programa de Pós-Graduação Integrado em Medicina. Universidade do Porto, Portugal. 42f. 2013. https://core.ac.uk/download/pdf/143402973.pdf

Garcia, J. L. Impacto da ingestão de carboidratos simples e gordura sobre parâmetros metabólicos, inflamatórios e pró-oxidantes no plasma e no tecido adiposo independente de obesidade. Dissertação-Mestrado Programa de Pós-Graduação em Patologia. Universidade $\begin{array}{lllllll}\text { Estadual Paulista, São } & \text { Paulo, } & \text { Brasil. } & 67 & \text { f. } & 2018 .\end{array}$ https://repositorio.unesp.br/handle/11449/153008.

Horstmann, S. W., Lynch, K. M., Arendt, E. K. (2017). Starch characteristics linked to glutenfree products. Foods, v. 6, n. 4, p. 29. https://doi.org/10.3390/foods6040029

Horwitz, W. Official methods of analysis of AOAC International. Washington: AOAC, 2000. 543p.

Huerta, K. M. Utilização de farinha de chia (Salvia hispânica L.) na elaboração de pão sem glúten sem adição de goma e gordura. Dissertação-Mestrado, Programa de Pós-Graduação em Ciência e Tecnologia dos alimentos. Universidade Federal de Santa Maria, Rio Grande do Sul, Brasil. 117f. 2015. http://repositorio.ufsm.br/handle/1/5778

FAO. Food and Agriculture Organization Food Wastage Footprint Impacts on natural resources Technical Report. Resources and Management Department, 2013. http://www.fao.org/3/i3347e/i3347e.pdf

Zenebon, O.; Pascuet, N. S.; Tiglea, P. Métodos físico-químicos para análise de alimentos. São Paulo: Instituto Adolfo Lutz, 2008. 1020p.

Layman, D. K. \& Baum, J. I. (2004). Dietary protein impact on glycemic control during weight loss. The Journal of nutrition, v. 134, n. 4, p. 968S-973S. https://doi.org/10.1093/jn/134.4.968S

Lima, J. P.; Portela, J. V. F.; Marques, L. R. et al. (2015). Farinha de entrecasca de melancia em biscoitos sem glúten. Ciência Rural, v. 45, n. 9, p. 1688-1694. https://doi.org/10.1590/0103$\underline{8478 \mathrm{cr} 20130209}$ 
Madineni, M. N.; Faiza, S.; Surekha, R. S. et al. (2012). Morphological, structural, and functional properties of maranta (Maranta arundinacea L) starch. Food Science and Biotechnology, v. 21, n. 3, p. 747-752. https://doi.org/10.1007/s10068-012-0097-y

Martins, G. A. Estatística geral e aplicada. São Paulo: Atlas, 2008. 421p.

Mendes, R. J. S. Biodiversidade e composição de alimentos: dados nutricionais de frutas nativas subutilizadas da flora brasileira. Dissertação-Mestrado, Programa de Pós-Graduação em Ciências. Universidade de São Paulo, São Paulo, 111f. 2015. http://www.teses.usp.br/teses/disponiveis/6/6138/tde-02122015-115143/en.php

Molz, P.; Pereira, C. S.; Gassen, T. L. et al. (2015). Relação do consumo alimentar de fibras e da carga glicêmica sobre marcadores glicêmicos, antropométricos e dietéticos em pacientes pré-diabéticos. Revista de Epidemiologia e Controle de Infecção, v. 5, n. 3, p. 131-135. http://dx.doi.org/10.17058/reci.v5i3.5585

Montes, S. S. Biscoito de farinhas de tapioca e de arroz: propriedades tecnológicas, nutricionais e sensoriais. Dissertação-Mestrado, Programa de Pós-Graduação em Ciência de Alimentos. Universidade Federal da Bahia, Salvador-Ba. 63f. 2014. https://silo.tips/download/universidade-federal-da-bahia-ufba-biscoito-de-farinhas-detapioca-e-de-arroz-pr

Navarro, M. E. L.; Santos, K. C. D.; Nascimento, A. F. D. et al. (2016). Inflamação renal, alterações metabólicas e oxidativas após 6 semanas de dieta de cafeteria em ratos. Jornal Brasileiro de Nefrologia, v. 38, n. 1, p. 9-14, 2016. https://doi.org/10.5935/01012800.20160003

Oliveira, J. E. D. \& Marchini, J. S. Ciências nutricionais: aprendendo a aprender. São Paulo: Sarvier, 2008. 760p.

O'shea, N., Rößle, C., Arendt, E. et al. (2015). Modelling the effects of orange pomace using response surface design for gluten-free bread baking. Food chemistry, v. 166, p. 223-230. https://doi.org/10.1016/j.foodchem.2014.05.157

Padalino, L., Conte, A., Del Nobile, M. A. (2016). Overview on the General Approaches to Improve Gluten-Free Pasta and Bread. Foods, v. 5, n. 87, p. 1-18. https://doi.org/10.3390/foods5040087

Padovani, R. M.; Amaya-Farfán, J.; Colugnati, F. A. B. et al. (2006). Dietary reference intakes: aplicabilidade das tabelas em estudos nutricionais. Revista de Nutrição, v. 19, n. 6, p. 741-760. https://doi.org/10.1590/S1415-52732006000600010

Pereira, B. S. (2013). Análise físico-química e sensorial do pão de batata isento de glúten enriquecido com farinha de chia. Revista Demetra, v. 8, n. 2, p. 125-136. 


\section{https://doi.org/10.12957/demetra.2013.5646}

R for Windows. Versão 4.1.0. The R Project for Statistical Computing, 2011. Software. https://cran.r-project.org/bin/windows/base/

Santos, A. A. O. et al. (2010). Desenvolvimento de biscoitos de chocolate a partir da incorporação de fécula de mandioca e albedo de laranja. Alimentos e Nutrição Araraquara, v. 21, n. 3, p. 469-480,

http://serv-bib.fcfar.unesp.br/seer/index.php/alimentos/article/viewArticle/1092

Santos, A. A. O.; Santos, A. J. A. O.; Silva, I. V. et al. (2010). Avaliação da influência das variáveis açúcar, polvilho azedo e albedo de laranja na elaboração de bolos de chocolate. Brazilian Journal of Food Technology, v. 16, n. 3, p. 175. https://doi.org/10.1590/S1981$\underline{67232013005000022}$

Scaramuzza, C. A. M. Brasil: $\mathbf{5}^{\mathbf{0}}$ relatório nacional para a Convenção Sobre Diversidade

Biológica. Brasília: MMA, 2016, 240p. disponível em:
images/abook/pdf/2017/Marco/Mar.17.39.pdf

Silva, N.; Junqueira, V. C. A.; Silveira, N. F. A.; Taniwaki, M. H.; Santos, R. F. S.; Gomes, R. A. R. (2010). Manual de métodos de análise microbiológica de alimentos e água. $4^{\circ}$ ed. São Paulo: Varela. 624p.

Silva, S. C. \& Cavalcante, A. K. S. (2014). Araruta: Cultivo e cultura integrados na melhoria do bem-estar e da renda familiar de pequenos produtores rurais. Revista Extensão, v. 7, n.1. https://www2.ufrb.edu.br/revistaextensao/images/revista/Revista $\% 20$ Extensao $\% 20-\% 206 \% 2$ 0Volume.pdf

Tarancón, P.; Sanz, T.; Fiszman, S. et al. (2014). Consumers' hedonic expectations and perception of the healthiness of biscuits made with olive oil or sunflower oil. Food research international, v. 55, p. 197-206. https://doi.org/10.1016/j.foodres.2013.11.011

Tirapegui, J. Nutrição: fundamentos e aspectos atuais. São Paulo: Atheneu. 477p.

Varzakas, T.; Zakynthinos, G.; Verpoort, F. (2016). Francis. Plant Food Residues as a Source of Nutraceuticals and Functional Foods. Foods, v. 5, n. 4, p. 88. https://doi.org/10.3390/foods5040088

Vieira, D. N. J. Agroecologia no Recôncavo Baiano: possibilidades e desafios. DissertaçãoMestrado, Programa de Pós-Graduação em Geografia. Universidade Federal da Bahia, Bahia, 121f. 2014. http://repositorio.ufba.br/ri/handle/ri/20258 
Financiamento: Este trabalho não recebeu financiamento.

Conflitos de interesse: Todos os autores declaram não haver conflito de interesses. Aprovação do comitê de ética: Não aplicável.

Disponibilidade dos dados de pesquisa Todos os dados gerados ou analisados neste estudo estão incluídos no manuscrito

\section{Contribuição dos autores}

Idealização: OLIVEIRA, Nayara Andrade de. ALMEIDA, Vanessa de Oliveira; Curadoria de dados: OLIVEIRA, Nayara Andrade de. ALMEIDA, Vanessa de Oliveira; metodologia: OLIVEIRA, Nayara Andrade de. ALMEIDA, Vanessa de Oliveira; revisão e edição: OLIVEIRA, Nayara Andrade de. 